\title{
Study of zinc oxide thin film characteristics
}

\author{
Shazlina Johari ${ }^{1}$, Nazalea Yazmin Muhammad ${ }^{1}$ and Mohd Rosydi Zakaria ${ }^{2}$ \\ ${ }^{1}$ School of Microelectronic Engineering, Universiti Malaysia Perlis, Pauh Putra Kampus, 02610 Arau, Perlis, Malaysia \\ ${ }^{2}$ Institute of Nano Electronic Engineering (INEE), Universiti Malaysia Perlis (UniMAP), Perlis, Malaysia
}

\begin{abstract}
This paper presents the characterization of $\mathrm{ZnO}$ thin films with the thickness of $8 \mathrm{~nm}, 30 \mathrm{~nm}$, and $200 \mathrm{~nm}$. The thin films were prepared using sol-gel method and has been deposited onto different substrate of silicon wafer, glass and quartz. The thin films were annealed at 400,500 and $600^{\circ} \mathrm{C}$. By using UV-Vis, the optical transmittance measurement were recorded by using a single beam spectrophotometer in the wavelength $250 \mathrm{~nm}$ to $800 \mathrm{~nm}$. However, the transmittance in the visible range is hardly influenced by the film thickness, substrate used and annealed temperature and the averages are all above $80 \%$. On surface morphology observed by AFM and FESEM, the results show that the increase of film thickness and annealed temperature will increase the mean grain size, surface-to-volume ration and RMS roughness. Besides that, higher annealing temperature cause the crystalline quality to gradually improve and the wurtzite structure of $\mathrm{ZnO}$ can be seen more clearly. Nonetheless, the substrate used had no effect on surface morphology, yet the uniformity of deposition on silicon wafer is better than glass and quartz.
\end{abstract}

\section{Introduction}

$\mathrm{ZnO}$ is considered as a versatile material with a very wide range of properties that include good transparency, high electron mobility, high thermal conductivity, wide bandgap, and strong room temperature luminescence [1-2]. Besides that, $\mathrm{ZnO}$ have attracted the interest of many research group due its application in light-emitting diodes (LED), laser diodes, field emission devices, solar cells gas sensors, surface acoustic wave, transparent contacts and thin film transistor (TFT) [1, 3-7, 8]. It was reported that $\mathrm{ZnO}$ thin films are highly transparent in the visible wavelength, also making it suitable for optoelectronic devices such as solar cells $[1,4,6]$. Moreover, it is chemically and mechanically stable, non-toxic, and high abundant. Thin film $\mathrm{ZnO}$ can be prepared by many methods and technique such as molecular beam epitaxy, atomic layer epitaxy, chemical vapor deposition, spray pyrolysis, sol-gel method, pulsed laser deposition, magnetron sputtering, electron beam evaporation, spin coating, thermal evaporation, electrochemical deposition, reactive evaporation [4 - 6]. Each of the technique has their own advantage and disadvantage but among all of these techniques, sol-gel method attracts much attention because it is low in cost, simple deposition equipment, easier adjustment of composition, able to carry out doping at molecular level, and easy fabricate on large-area films [5].

There are many factors that affect the performance of the optical and structural properties of $\mathrm{ZnO}$ thin film such as annealing temperature of thin film, the preparation method of the thin film, substrate that are used and the thickness of thin film. In terms of the annealing temperature, the thin films have been reported to be typically annealed at different temperature ranging from $200^{\circ} \mathrm{C}$ to $800^{\circ} \mathrm{C}$ while thickness of $\mathrm{ZnO}$ usually are varied from $40 \mathrm{~nm}$ to $360 \mathrm{~nm}$. Furthermore, substrate that are commonly used with $\mathrm{ZnO}$ are glass, quartz and silicon. With regards to the preparation technique, $\mathrm{ZnO}$ thin films can be prepared using two methods, which are chemical deposition and physical deposition. For the chemical deposition, it contains spin coating process, spray pyrolysis process and dip coating process while for the physical deposition, it is divided into two parts, which are evaporation and sputter deposition

Although many works have been done to investigate the properties of $\mathrm{ZnO}$ thin film, it is still questionable which method and factor influence the performance of the thin film the most. These factors include $\mathrm{ZnO}$ solution concentration, preheating temperature, post-annealing temperature, annealing atmosphere, film thickness and so on [5]. Between all these factors, the influence of film thickness on structural, optical and electrical properties of $\mathrm{ZnO}$ thin films (especially undoped $\mathrm{ZnO}$ thin films) derived from sol-gel method was less studied. Moreover, there are still many differences between the results that have been reported. In order to obtain high-quality optoelectronic devices based on $\mathrm{ZnO}$ thin films, it is very significant to deeply investigate the effect of the film parameters such as film thickness.

This paper aims to investigate the structure, morphology and optical properties of $\mathrm{ZnO}$ using Field

\footnotetext{
*Corresponding author: shazlinajohari@unimap.edu.my
} 
Emission Scanning Electron Microscopy (FESEM), Atomic force microscopy (AFM) and ultraviolet-visible spectrometry (UV-Vis) techniques and determine the best thin film parameter in terms of thickness, annealed temperature and substrate used that could produce optimum surface morphology and high transmission rate.

\section{Methodology}

Initially the substrate (quartz, glass or silicon wafer) was cleaned with chemical (acetone + ethanol + isopropanol) using ultrasonic machine for 10 minutes to remove the contaminants on the surface of the substrate. Zinc acetate dehydrate had to be dissolved in mixture of 2-methoxyethanol and mono-ethanolamine. After that, the mixture solution was stirred by using a magnetic stirrer at $60^{\circ} \mathrm{C}$ for 2 hours using a hot plate and stirrer. The solution is then left for 24 hours at room temperature. Solution was coated on a substrate (quartz, glass, and silicon) at $3000 \mathrm{rpm}$ for 60 seconds. Then precursor thin films (sample) were heated at $150^{\circ} \mathrm{C}$ for 10 minutes and after that, coating and heating process were repeated for 10 times depending on the thickness of the solution $(\mathrm{ZnO})$. The films were inserted into the furnace and annealed in ambient atmosphere at several temperatures $\left(400^{\circ} \mathrm{C}, 500^{\circ} \mathrm{C}\right.$ and $\left.600^{\circ} \mathrm{C}\right)$. Samples are characterized using Atomic Force Microscope (AFM), UV-visible Spectrophotometer and Field Emission Scanning Electron Microscopy (FESEM) to observe the structural and optical properties. Then, observation was made in each different parameter in every characterization equipment and identify the differences.

Atomic Force Microscopy (AFM) is essential for the visualization and measurement of nanometre scale structures. This equipment is a combination of the principle of the scanning tunnelling microscope and the stylus profilometer. Meanwhile, ultraviolet-visible spectroscopy or ultraviolet-visible spectrophotometry (UV-Vis or UV/Vis) refers to absorption spectroscopy or reflectance spectroscopy in the ultravioletvisible spectral region. This means, it uses light in the visible and adjacent ranges. FESEM is microscope that works with electrons (particles with a negative charge) instead of light and the electrons are liberated using a field emission source. In addition, FESEM is an advance technology of SEM because it have a better resolution and more focus beam [9].

\section{Results and Discussion}

First, observation was made to investigate the effect of annealing temperature which was varied from $400{ }^{\circ} \mathrm{C}$, $500{ }^{\circ} \mathrm{C}$ and $600{ }^{\circ} \mathrm{C}$ towards the thin film. The morphology and topography of the thin films were observed and compared using AFM and FESEM. Figure 1 shows the topography of the thin film with different annealing temperature. The thickness of film is set to be constant to approximately $8 \mathrm{~nm}$.
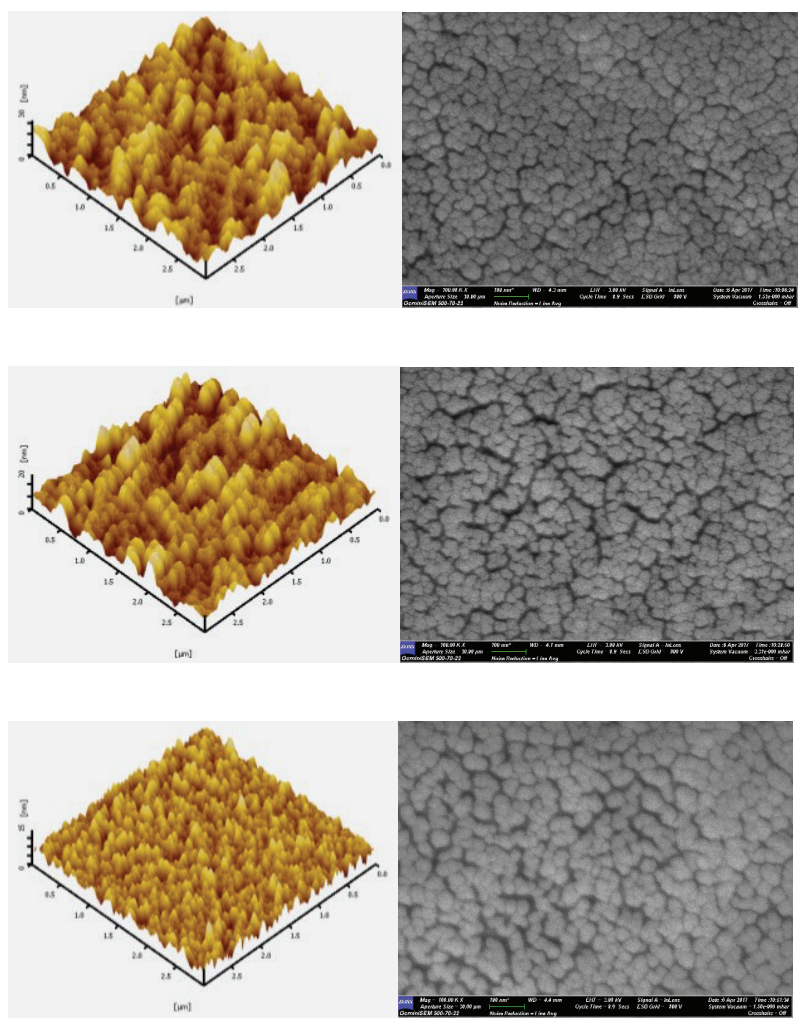

Fig. 1. AFM and FESEM images of $\mathrm{ZnO}$ with $30 \mathrm{~nm}$ thickness deposited on Silicon substrate annealed at different temperature of. (a) $400^{\circ} \mathrm{C}$ (b) $500^{\circ} \mathrm{C}$ (c) $600^{\circ} \mathrm{C}$

The RMS roughness of the grain are $0.7337 \mathrm{~nm}$, $0.8209 \mathrm{~nm}, 0.8344 \mathrm{~nm}$ for $400^{\circ} \mathrm{C}, 500^{\circ} \mathrm{C}$ and $600^{\circ} \mathrm{C}$ respectively. Therefore, the RMS roughness increases as the annealed temperature increases. The RMS roughness increases due to increases in grain size and the crystalline quality improved as the annealed temperature increases. For all samples annealed at all the varied temperature, the peak of the grain are sharp and pointed and the grain boundaries is clear. Besides that, the uniformity is good and the surface is smooth because the RMS roughness is less than $1 \mathrm{~nm}$. This trend is similar and comparable with the work reported by [7], where they also confirmed that annealing temperature has direct influence over the roughness of the grain structure.

The film thickness was also varied in deposition process using a spin coater. The layer of $\mathrm{ZnO}$ was build up to $8 \mathrm{~nm}$ (one layer), 30nm (three layers) and $200 \mathrm{~nm}$ (six layers). The differences in film thickness of $\mathrm{ZnO}$ was observed using AFM and FESEM to study the morphology and topography of the $\mathrm{ZnO}$ thin film. Figure 2 shows the morphology surface of the $\mathrm{ZnO}$ thin film scanned by FESEM. The magnification used to scan the thin film was $50 \mathrm{k}$ times and $100 \mathrm{k}$ times. In one layer of $\mathrm{ZnO}$, the structure size of the $\mathrm{ZnO}$ was very small, smooth and had a good uniformity.

On the other hand, in three layers of $\mathrm{ZnO}$, the size of structure was bigger than one layer of $\mathrm{ZnO}$ and the quality of crystalline was improved. The layer of overlapped $\mathrm{ZnO}$ can be seen in the three layers FESEM image because of the repetition in deposition process. Lastly, in six layers of $\mathrm{ZnO}$, the overlapping of $\mathrm{ZnO}$ was 

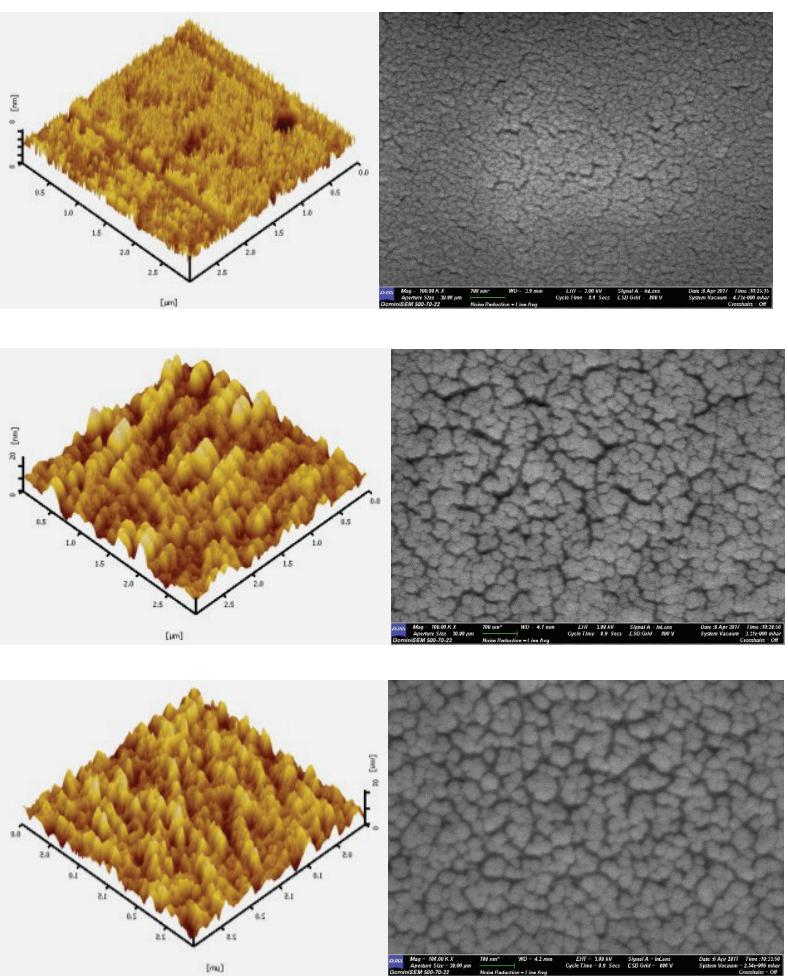

Fig. 2. AFM and FESEM images of $\mathrm{ZnO}$ deposited on Silicon substrate annealed at $500^{\circ} \mathrm{C}$ with different thickness of (a) $8 \mathrm{~nm}$ (b) $30 \mathrm{~nm}$ (c) $200 \mathrm{~nm}$

clear and the uniformity decreases. Despite that, the quality of crystalline in six layers was greater compared to three layers. Moreover, the size of the $\mathrm{ZnO}$ structure also increase as the thickness increases.

We also compared the physical properties of $\mathrm{ZnO}$ deposited on different substrate, as shown in Figure 3 where it shows the result of $30 \mathrm{~nm} \mathrm{ZnO}$ annealed at $400^{\circ} \mathrm{C}$ with different substrate. The morphology and topography of these films were observed to differentiate it. It can be seen that the differences between the substrate were obvious. The thickness of film were $8 \mathrm{~nm}$, $60 \mathrm{~nm}$ and $6 \mathrm{~nm}$ for Silicon wafer, glass and quartz respectively. Meanwhile, surface analysis shows that silicon wafer, glass and quartz have $0.8044 \mathrm{~nm}, 5.617 \mathrm{~nm}$ and $69.68 \mathrm{~nm}$ in RMS roughness respectively. Silicon had a smooth and uniform structure. That is why silicon RMS roughness and the thickness value was small. Moreover, the peak of the grain were sharp and pointed and the grain boundaries was clear. The growth mode is vertical growth and the grain size was small. Next, for glass substrate, the uniformity was decreased, which formed a thicker layer of $\mathrm{ZnO}$ than in silicon and quartz but the surface was smooth because the RMS roughness was only $5.617 \mathrm{~nm}$. The peak of the grain were round and the surface of the film appeared flat, which make the grain boundaries less clear. However, the growth mode of glass was still in vertical direction. Lastly, in quartz, the thickness was small but the RMS roughness were high. The surface was very rough which make it difficult for AFM to scan the entire surface clearly. In addition, quartz have an issue with uniformity but the growth mode was in lateral direction because the crystalline quality improved and at the same time, resulting in the grain to became rough.
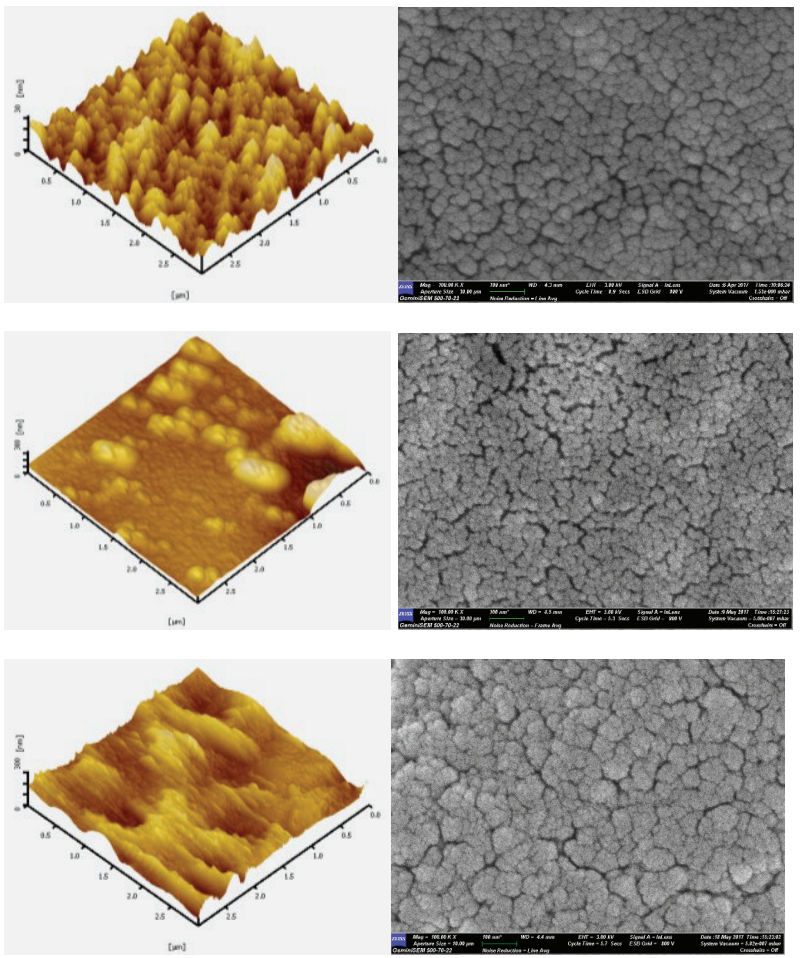

Fig. 3. AFM and FESEM images of $\mathrm{ZnO}$ annealed at $400^{\circ} \mathrm{C}$ with thickness of $30 \mathrm{~nm}$ on different substrates (a) Silicon (b) Glass (c) Quartz

In terms of optical properties obtained, $\mathrm{ZnO}$ deposited on quartz substrate achieved the highest transmittance percentage, which is $90 \%$. Meanwhile, for $\mathrm{ZnO}$ deposited on glass, the transmittance was more than $80 \%$ but it did not reach $90 \%$. Nonetheless, the curve of both graph were similar. At wavelength of $400 \mathrm{~nm}$, the transmittance percentage of $\mathrm{ZnO}$ using glass substrate increase slightly until $800 \mathrm{~nm}$. On the other hand, the transmittance percentage for $\mathrm{ZnO}$ when using quartz as substrate, increase dramatically and maintained the transmittance percentage until $700 \mathrm{~nm}$. Therefore, it can be concluded that, quartz was a better substrate having a high transparency in visible region.

The optical properties are investigated by varying the film thickness and the annealing temperature, as depicted in Figure 4. The high transmittance in visible region was good for the optical performance of the thin film. From the graph, in terms of annealing temperature parameter, it have proved that $400^{\circ} \mathrm{C}$ have the best transmittance. Then thickness was varied at $400^{\circ} \mathrm{C}$ to study the effect of thickness. The highest transmittance percentage was one layer of $\mathrm{ZnO}$ with the percentage more than $80 \%$. Then, it followed by six and three layers. This proved that as the film thickness decreases, the increases of wavelength would increase the transmittance percentage too. Nevertheless, the result was not consistent because in some of the results, it seems like the film thickness did not affect the transmittance. 

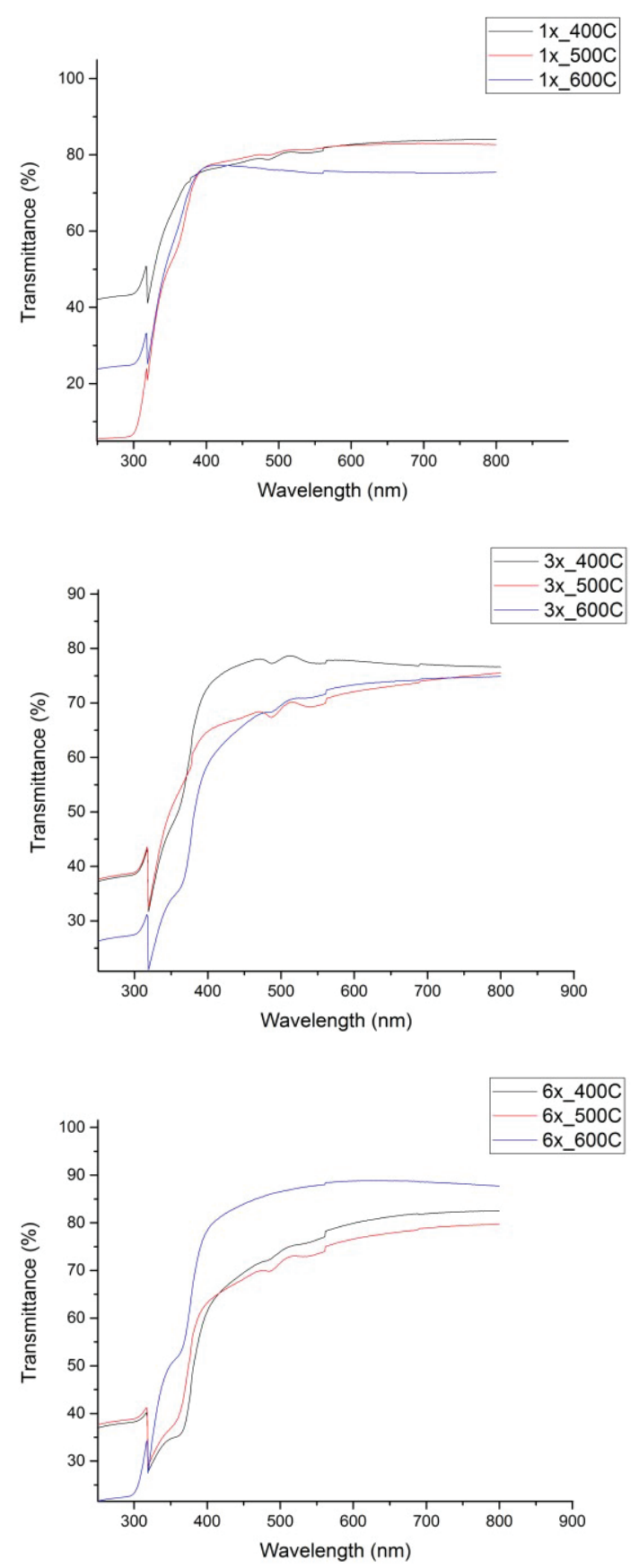

Fig. 4. Transmittance spectra of $\mathrm{ZnO}$ thin films with different thickness.

\section{Conclusion}

From the structural properties of $\mathrm{ZnO}$ obtained from this work, we concluded that the best film thickness is one layer of $\mathrm{ZnO}(8 \mathrm{~nm})$, and the best annealing temperature is $600^{\circ} \mathrm{C}$. Furthermore, the best substrate used is silicon wafer. This, however, depends on the potential application of thin film. Nonetheless, for the optical properties, parameter that achieved the highest transmittance percentage is when one layer $\mathrm{ZnO}$ is deposited on quartz substrate and annealed at $400^{\circ} \mathrm{C}$. In order to have a high quality of thin film, many criteria have to be investigated to find the best results that suits the requirement of thin film. For the future studies, the other parameters that can be tested and studied are the reliability of the $\mathrm{ZnO}$ thin film, by using a different type of material to dope with the $\mathrm{ZnO}$. and by using different type of method to prepare the $\mathrm{ZnO}$. If all the parameters have been optimized, $\mathrm{ZnO}$ can have a number of applications, making it a very versatile material. It has already made its way into MEMS devices and its nano characteristics and the uses are continuing to be explored. There are a lot of potential for zinc oxide, and other uses for this material will continue to be discovered and explored.

We are grateful for the funding provided by FRGS 9003:00405 and the authors would like to thank School of Microelectronic (SoME), Universiti Malaysia Perlis for their technical assistance and supports.

\section{References}

1. A. Janotti and C. G V. d. Walle, Rep. Prog. Phys., 72, pp. 29 (2009)

2. R. Kumar, G. Kumar, O. Al-Dossary and A. Umar, Mater. Express, 5, No 1 (2015)

3. S.Sanjeev and D.Kekuda, "IOP Conf. Series: Materials Science and Engineering, 73, (2015)

4. J.Lv, W.Gong, K.Huang, J.Zhu, F.Meng, X.Song, and Z.Sun, Superlattices and Microstructures, 50, pp. 98-106 (2011)

5. L.Xu, X.Li, Y.Chen, and F.Xu, Applied Surface Science, 257, pp. $4031-4037$ (2011)

6. Y. Aoun, B. Benhaoua, S. Benramache, and B. Gasmi, ” Optik 126, pp. 5407-5411 (2015).

7. S. S. Shariffudin, N. T. C. Ibrahim, M. S. P. Sarah, and H. Hashim, IEEE-ICSE2016 Proc., (2016)

8. S.M.S, IJRSET, 2, pp. 19-24 (2015)

9. H. Yao, and K. Kimura, Modern Research and Educational Topics in Microscopy (2007) 